\title{
Risk factors of severe pneumonia among children: A hospital based case control study in Lahore, Pakistan.
}

1. Ph.D Scholar

Epidemiology \& Public Health

University of Veterinary \& Animal

Sciences (UVAS), Lahore Pakistan

2. Ph.D (Medicine)

Associate Professor Epidemiology \& Public Health

University of Veterinary \& Animal

Sciences (UVAS), Lahore Pakistan

3. Ph.D

Scholar Epidemiology \& Public Health

University of Veterinary \& Animal

Sciences (UVAS), Lahore Pakistan.

Correspondence Address:

Dr. Chanda Jabeen

University of Veterinary \& Animal

Sciences (UVAS),

Lahore Pakistan.

chandajabeen786@gmail.com

Article received on:

05/10/2020

Accepted for publication:

$12 / 02 / 2021$

\section{Chanda Jabeen ${ }^{1}$, Muhammad Hassan Mushtaq ${ }^{2}$, Gulshan Umbreen ${ }^{3}$}

ABSTRACT... Objective: To identify the risk factors of severe pneumonia among children 2-59 months of age in a Tertiary Care Hospital Lahore, Pakistan. Study Design: Case Control study. Setting: Mayo Hospital Lahore. Period: December 2016 to March 2017. Material \& Methods: Cases were 162. Controls were selected in 1:1. Sample size was 162 cases and 162 controls. Purposive sampling technique was used. Informed consent taken from each participant before collection of data. Structured questionnaire was used. Data was analyzed through SPSS 20.0. Chi square and binary logistic regression was applied. Results: Low socio economic conditions, low maternal and parental education, contact with the member having upper respiratory tract infection, having contact with member suffering from URTI, hospitalization due to diarrheal illness and being underweight were found strongly associated with severe pneumonia (having odds ratios more than 1) among children 2-59 months of ages in this study. Conclusion: Poverty, illiteracy of parents and having contact with member having respiratory infection and underweight are potential risk factors of severe pneumonia.

Key words: Children 2-59 Months of Age, Case-Control Study, Severe Pneumonia.

Article Citation: Jabeen C, Mushtaq MH, Umbreen G. Risk factors of severe pneumonia among children: a hospital based case control study in Lahore, Pakistan. Professional Med J 2021; 28(10):1470-1476. https://doi.org/10.29309/TPMJ/2021.28.10.6128

\section{INTRODUCTION}

In children acute respiratory infections are the most common cause of high morbidity and mortality worldwide. Every year many children are suffering from pneumonia out of which $11.5 \%$ progress to sever pneumonia. ${ }^{1}$

Pneumonia is an infectious disease which causes inflammation of alveoli and airway structure of lungs. Pneumonia causes infant and children morbidity and mortality significantly. Infants are two times on risk of having pneumonia as compared to older children. Respiratory tract infection is most common infection among children. It spreads through droplet infection. Epidemics of pneumonia occur in winter and spring. The sign and symptoms of the pneumonia are fever, cough, stridor, wheezing, tachypnea and respiratory distress. ${ }^{2}$ Risk factors of pneumonia are less socio economic status, indoor crowding, indoor pollution, contact with the persons having acute respiratory illness, poor access to health facilities and lower maternal education status. ${ }^{3}$ Direct contact with contaminated respiratory secretions between household members, infants, and children is the common mode of transmission of pneumococcus. ${ }^{4}$

According to WHO Pneumonia accounts for $15 \%$ of all deaths of children under 5 years old, killing an estimated 922000 children in 2015. Worldwide each year estimated new episodes of childhood pneumonia are 156 million, out of which 151 million episodes of pneumonia estimated in developing countries. 43 million cases of pneumonia occur in India, 21 million in China and 10 million in Pakistan. ${ }^{6}$

Overall incidence of pneumonia in Pakistan is 0.26 episodes per child per year. Highest incidence found in children less than 12 months of age as they have 0.42 episodes per child per year. Incidence of pneumonia decreases with the age of the child. In neonatal period $28 \%$ death 
attributed to the pneumonia and the incidence of invasive pneumococcal disease was 25 episodes per 100000 child per years. ${ }^{7}$ Globally pneumonia considered No 1 among infectious disease which causes 935,000 mortality in children under five years of age and killing 25000 children per day. ${ }^{8}$ In Pakistan for pneumonia the total societal average cost per episode is US\$22.62 and for severe pneumonia total societal average cost per episode is US\$142.90. So in Pakistan pneumonia is not only the leading killer of children but also a high economic burden to society. ${ }^{9}$

So having knowledge of risk factors of pneumonia is very important. Pneumonia and pneumonia related deaths are prevented by controlling the risk factors of pneumonia in children under 5 years of age. There is also a strong economic justification for introducing preventive measures. In Pakistan less case control studies were conducted on present study topic.

\section{MATERIAL \& METHODS}

This study was conducted at Mayo Hospital Lahore. Research design was Analytical observation. An unmatched case control study was conducted for a period of three months (December 2016 to March 2017) in order to identify risk factors of severe pneumonia among children under five years of age in Lahore.

Children 2-59 months of age meeting the case definitions admitted in the Tertiary Care Hospital Lahore were selected as case and children meeting the control criteria were selected as control. Children above 59 months of age and adults admitted in the Tertiary Care Hospital Lahore were excluded. Purposive sampling technique was used.

Children who were suffering from other lower respiratory tract diseases including bronchiolitis, lung abscess, acute bronchitis and children's guardian who refused to participate were also excluded from the study.

For sample size calculation, we used STATCALC (Epilnfo 7d), with the following parameters: estimated rate of $22.5 \%$ of children unvaccinated with pneumococcal vaccine in the control group, $80 \%$ statistical power to detect an odds ratio (OR) equal to 2.0 , with an alpha error of $5 \%$ and a proportion of 1 case for 1 control. The sample size was 324 patients (162 cases and 162 controls).

Case definition of severe pneumonia by WHO

- Fast breathing: $\geq 50$ breaths/min in a child aged $2-11$ months $\geq 40$ breaths $/ \mathrm{min}$ in a child aged $1-5$ years

- Fast breathing with/or chest indrawing including danger signs e.g. inability to breastfeed or drink or may experience reduced level of consciousness, hypothermia and convulsions that require hospitalization. ${ }^{10}$

\section{Cases}

Children who meet the case definition of severe pneumonia were selected as cases.

\section{Controls}

Children who do not have rapid respiratory rate and chest indrawing, inability to breastfeed or drink, reduced level of consciousness, hypothermia and convulsions were selected as controls.

Permission to conduct study was taken from IRB of concerned university and written informed consent was signed by each participant's guardian (case and control) and briefly informed them about questionnaire and purpose of study.

The data was collected from the child's guardians admitted in a tertiary care hospital. Cases and controls were included and data about their sociodemographic characteristics and various other risk factors were collected through questionnaire.

WHO charts of weight for age were used to determine the underweight for both boys and girls separately. Children whose weight was - 2 SD below the normal weight were considered underweight.

Overcrowding was measured by using person per bed room criteria given by U.S. Department of Housing and Urban Development Office of Policy Development and Research. ${ }^{11}$ 
Reliability of the research tool was measured by Chronbach's Alpha which is 0.61 (strong). Convergent validity was established by applying factor analysis and value of $\mathrm{KMO}$ was calculated 0.8 with Bartlett at 0.000 .

Data was analyzed through SPSS 20.0. Chi square test was used to check the association of each of the categorical variable with severe pneumonia and by odds ratio the strength of their association was computed through binary logistic regression at a significance level of $95 \%$.

\section{RESULTS}

The present study was conducted to assess the risk factors associated with severe pneumonia among children 2 to 59 months of age in Mayo Hospital Lahore.

\section{DISCUSSION}

Significant relationship found between parental education and presence of severe pneumonia among children under 5 years of age. In present study poverty was found a risk factor of severe pneumonia. As Table II showed strength of association between different independent variables and severe pneumonia. Strong association found between exclusively breastfeeding and severe pneumonia as p-value is 0.002 less than 0.05 . Those babies who were not exclusively breastfed had great risk for severe pneumonia. Risk for severe pneumonia was 6.7 times higher in not exclusively breastfed children than the exclusively breastfed. Children who had diarrhoea were 9.9 times on risk for severe pneumonia. Statistically significant association found between contact with member of household with upper respiratory tract infection (URTI) and severe pneumonia as $p$ value is 0.002 less than 0.05. Children who had contact with the member of household with URTI were 9.9 times at greater risk for severe pneumonia. Risk of severe pneumonia was 10 times higher in children who were under weight than the normal weight children.

\begin{tabular}{|c|c|c|c|c|}
\hline & Cases & Controls & P-Value & Chi square value \\
\hline $\begin{array}{l}\text { Mother's Education Level } \\
\text { Illiterate } \\
\text { Up to Matric } \\
\text { Above Matric }\end{array}$ & $\begin{array}{c}105 \\
50 \\
7\end{array}$ & $\begin{array}{c}34 \\
112 \\
16\end{array}$ & $0.000 *$ & 63.516 \\
\hline $\begin{array}{l}\text { Mother's Occupation } \\
\text { House wife } \\
\text { Working women }\end{array}$ & $\begin{array}{c}161 \\
1\end{array}$ & $\begin{array}{c}160 \\
2\end{array}$ & 0.562 & 0.336 \\
\hline $\begin{array}{l}\text { Mother's Income } \\
\text { No Income } \\
\text { Less than } 15,000 \\
15,000-20,000\end{array}$ & $\begin{array}{c}160 \\
2 \\
0\end{array}$ & $\begin{array}{c}60 \\
1 \\
1\end{array}$ & 0.513 & 1.333 \\
\hline $\begin{array}{l}\text { Father's Education Level } \\
\text { Illiterate } \\
\text { Up to Matric } \\
\text { Above Matric }\end{array}$ & $\begin{array}{l}60 \\
85 \\
17\end{array}$ & $\begin{array}{l}40 \\
94 \\
28\end{array}$ & $0.028^{*}$ & 7.141 \\
\hline $\begin{array}{l}\text { Father's Occupation } \\
\text { Business man } \\
\text { Labourer } \\
\text { Servant }\end{array}$ & $\begin{array}{c}37 \\
100 \\
25\end{array}$ & $\begin{array}{l}51 \\
83 \\
28\end{array}$ & 0.137 & 3.976 \\
\hline $\begin{array}{l}\text { Father's Income } \\
\text { Less than } 96.80 \text { USD } \\
\text { 96.80 USD - } 129.06 \text { USD } \\
135.51 \text { USD - } 161.33 \text { USD }\end{array}$ & $\begin{array}{c}92 \\
64 \\
6\end{array}$ & $\begin{array}{l}66 \\
71 \\
25\end{array}$ & $0.000 *$ & 16.287 \\
\hline
\end{tabular}




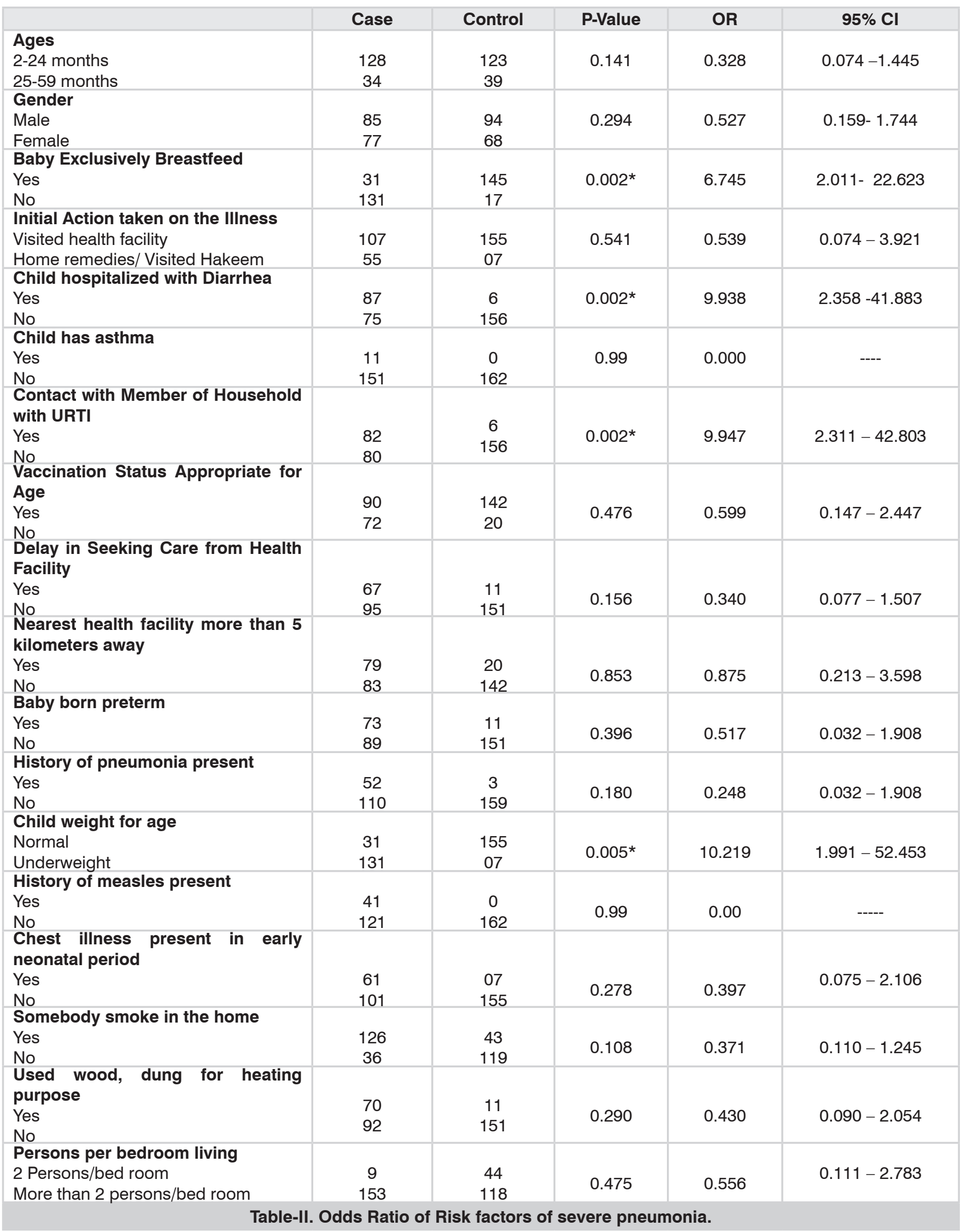


In this study there is a significant relationship found between mother's education level and severe pneumonia. Mother's illiteracy is one of the risk factor of severe pneumonia among children less than 5 years of age. Father illiteracy found significant in present study.

Mother has a very close association with child and she is the person who recognizes the minor changes in the health of the child. If mother is illiterate and do not have knowledge about the diseases symptoms air severity it affect the child health. So mother's illiteracy has a great impact on child health than father's illiteracy. ${ }^{12}$

In present study significant association found between father's income and presence of severe pneumonia among children 2-59 months of age as $p$ value is 0.000 less than 0.05 . Low socioeconomic factor is also a risk factor of severe pneumonia. As children of wealthy parents get treatment from professional qualified doctors and they get treatment timely too which decrease the risk of complications and severity of diseases. ${ }^{13}$ Low socio economic status is a strong predictor off severe pneumonia among children below five years of age in low income and developing countries. ${ }^{14}$ Result of this study is correlated with the study conducted by Kosai et al in which significant association found between low socio economic status and severe pneumonia. Risk for severe pneumonia is 1.3 times higher in children who had low socio economic status than others. ${ }^{15}$

In this study strong association is present between exclusive breast feeding and severe pneumonia. Risk for severe pneumonia found six times higher in children not exclusively breastfed as compared to those who were breastfed.

Results of this study are opposite to the case control study conducted in Karnataka In this study no significant association found between exclusive breast feeding and severe pneumonia as $p$ value was 0.72 which was more than $0.05 .{ }^{16}$

Strong association is present between presence of diarrheal illness and severe pneumonia. Diarrhoea causes malnourishment in children which predispose them to severe pneumonia. Result of this study was opposite to the study case control study conducted in Kenya where no significant association was present between diarrhoea and severe pneumonia. ${ }^{17}$ Similar results found in the study conducted by Ashraf at el in Karachi, in which strong association was present between diarrhoea and pneumonia in children under 5 years of age. ${ }^{18}$

In present study contact with the member of Upper respiratory tract infection was strongly associated with the severe pneumonia.

Viruses which cause upper respiratory tract infection are responsible for severe pneumonia among children these viruses includes Respiratory syncytial virus (RSV), Para influenza virus, influenza and adenovirus. ${ }^{19}$ Onyango at el conducted an un matched case control study in Kenya found that children who had contact with member suffering from upper respiratory tract infection were 2.82 times on risk for severe pneumonia as compared to those who did not have contact with the member suffering from upper respiratory tract infection. ${ }^{17}$

Present study showed strong association between child weight for age and severe pneumonia as $p$ value is 0.002 less than 0.05 . Odds of having severe pneumonia are 15 times higher in children who are under weight than the normal weight children.

Malnourishment leads to immune compromised state which in turn increases the risk of severe pneumonia among children 2-59 months of ages. ${ }^{20}$

Study conducted in Ecuador also showed underweight a risk factor of severe pneumonia. This study was a doubled blind, placebo controlled study found risk of having severe pneumonia in underweight children were 1.8 times higher compared to the normal weight children ages of 2-59 months of age. ${ }^{21}$

\section{CONCLUSION}

Many risk factors were significantly associated with 
severe pneumonia among children 2-59 months of age like low socio economic conditions, low maternal and parental education, contact with the member having upper respiratory tract infection, having contact with member suffering from URTI, hospitalization due to diarrheal illness and being underweight were found strongly associated with severe pneumonia (having odds ratios more than 1) among children 2-59 months of ages in this study.

\section{Copyright $(12$ Feb, 2021.}

\section{REFERENCES}

1. Rudan I, O'brien KL, Nair H, Liu L, Theodoratou E, Qazi S, Lukšić I, Walker CL, Black RE, Campbell $\mathrm{H}$, Child Health Epidemiology Reference Group. Epidemiology and etiology of childhood pneumonia in 2010: estimates of incidence, severe morbidity, mortality, underlying risk factors and causative pathogens for 192 countries. Journal of global health. 2013 Jun;3(1).

2. Condon VR. Pneumonia in children. Journal of thoracic imaging. 1991; 6(3):31-44.

3. Wonodi CB, Deloria-Knoll M, Feikin DR, DeLuca AN, Driscoll AJ, Moïsi JC, et al. Evaluation of risk factors for severe pneumonia in children: The Pneumonia Etiology Research for Child Health study. Clinical infectious diseases. 2012; 54(suppl 2):S124-S31.

4. Van der Poll T, Opal SM. Pathogenesis, treatment, and prevention of pneumococcal pneumonia. The Lancet. 2009; 374(9700):1543-56.

5. WHO. Pneumonia. World Health Organization 2015 Cited 201625 August.

6. Rudan I, Boschi-Pinto C, Biloglav Z, Mulholland K, Campbell $\mathrm{H}$. Epidemiology and etiology of childhood pneumonia. Bulletin of the World Health Organization. 2008; 86(5):408-16B.

7. Owais A, Tikmani SS, Sultana S, Zaman U, Ahmed I, Allana $S$, et al. Incidence of pneumonia, bacteremia, and invasive pneumococcal disease in Pakistani children. Tropical Medicine \& International Health. 2010; 15(9):1029-36.
8. Liu L, Oza S, Hogan D, Perin J, Rudan I, Lawn JE, et al. Global, regional, and national causes of child mortality in 2000-13, with projections to inform post2015 priorities: an updated systematic analysis. The Lancet. 2015; 385(9966):430-40.

9. Hussain H, Waters H, Khan AJ, Omer SB, Halsey NA. Economic analysis of childhood pneumonia in Northern Pakistan. Health policy and planning. 2008; 23(6):438-42.

10. WHO. Pocket book of hospital care for children: Guidelines for the management of common childhood illnesses: World Health Organization; 2013.

11. Blake KS, Kellerson RL, Simic A. Measuring overcrowding in housing. Washington, DC: Department of Housing and Urban Development, Office of Policy Development and Research. 2007.

12. Taksande AM, Yeole M. Risk factors of Acute Respiratory Infection (ARI) in under-fives in a rural hospital of Central India. Journal of Pediatric and Neonatal Individualized Medicine (JPNIM). 2015; 5(1):e050105.

13. Hadi A. Management of acute respiratory infections by community health volunteers: Experience of Bangladesh Rural Advancement Committee (BRAC). Bulletin of the World Health Organization. 2003; 81(3):183-9.

14. Sonego M, Pellegrin MC, Becker G, Lazzerini M. Risk factors for mortality from acute lower respiratory infections (ALRI) in children under five years of age in low and middle-income countries: A systematic review and meta-analysis of observational studies. PloS one. 2015; 10(1):e0116380.

15. Kosai H, Tamaki R, Saito M, Tohma K, Alday PP, Tan $A G$, et al. Incidence and risk factors of childhood pneumonia-like episodes in Biliran Island, Philippines-a community-based study. PloS one. 2015; 10(5):e0125009.

16. Ramesh K, Varshithal. H, Ashray. V, Safna. C. T, N A. Risk factors for severe pneumonia in children: A hospital based case - control study. Journal of Evolution of Medical and Dental Sciences. 2012; 1(4):357-70.

17. Onyango D, Kikuvi G, Amukoye E, Omolo J. Risk factors of severe pneumonia among children aged 2-59 months in western Kenya: A case control study. Pan African Medical Journal. 2012; 13(1).

18. Ashraf $\mathrm{S}$, Huque $\mathrm{MH}$, Kenah $\mathrm{E}$, Agboatwalla $\mathrm{M}$, Luby SP. Effect of recent diarrhoeal episodes on risk of pneumonia in children under the age of 5 years in Karachi, Pakistan. International journal of epidemiology. 2013; 42(1):194-200. 
19. Budge PJ, Griffin MR, Edwards KM, Williams JV, Verastegui H, Hartinger SM, et al. A household-based study of acute viral respiratory illnesses in Andean children. The Pediatric infectious disease journal. 2014; 33(5):443-7.

20. Mir AA, Imtiyaz A, Fazili A, Iqbal J, Jabeen R, Salathia A. Prevalence and risk factor analysis of acute respiratory tract infections in rural areas of Kashmir valley under 5 Years of Age. International Journal of Medicine and Public Health. 2012; 2(3).
21. Jonnalagadda S, Rodríguez O, Estrella B, Sabin LL, Sempértegui F, Hamer DH. Etiology of severe pneumonia in Ecuadorian children. PloS one. 2017; 12(2):e0171687.

\begin{tabular}{|c|c|c|c|}
\hline \multicolumn{3}{|c|}{ AUTHORSHIP AND CONTRIBUTION DECLARATION } \\
\hline Sr. \# & Author(s) Full Name & \multicolumn{1}{|c|}{ Contribution to the paper } & Author(s) Signature \\
\hline 1 & Chanda Jabeen & $\begin{array}{l}\text { Concept design, Research plan, } \\
\text { Introduction, Literature review, methodology, } \\
\text { Data collection analysis, Discussion and } \\
\text { review, Proof reading, Drafting the article. } \\
\text { Supervision, Revising it critically for proof } \\
\text { intellectual contents. } \\
\text { Data collection, Interpretation and results. }\end{array}$ \\
\hline 3 & M. Hassan Mushtaq & \\
\hline
\end{tabular}

